\title{
Opportunities to Enhance Tourism Industry Development: Gambella People's National Regional State, South West Ethiopia
}

\author{
Selemon Thomas Fakana*, Alemken Berihun Mengist \\ Department of Wildlife and Ecotourism Management, College of Agriculture and Natural Resources, Gambella University, Gambella, \\ Ethiopia
}

Email address:

selethom36@gmail.com (S. T. Fakana)

${ }^{*}$ Corresponding author

\section{To cite this article:}

Selemon Thomas Fakana, Alemken Berihun Mengist. Opportunities to Enhance Tourism Industry Development: Gambella People's National Regional State, South West Ethiopia. International Journal of Hospitality \& Tourism Management. Vol. 3, No. 2, 2019, pp. 18-24.

doi: $10.11648 /$ j.ijhtm.20190302.11

Received: July 22, 2019; Accepted: August 18, 2019; Published: November 21, 2019

\begin{abstract}
Tourism has been emerged as one of the effective tools in eradicating poverty. Ethiopia has huge tourism potentials like natural, non-natural, historical and cultural resources. Gambella Region is one of the attractive tourismdestinations located at South West of Ethiopia. But, its tourism industry development is in infant stage. Nonetheless, limited study has carried out on identifying opportunities. Hence, the main objective of this study was identifying opportunities to enhance tourism industry development in the Region. To do so, key informants from three zones, five regional offices and thirteen woredas has purposively selected based on the defined criteria. Altogether, 103 key informants were interviewed besides to field observation. The collected firsthand data were edited, categorized, arranged and organized and encoded into SPSS software version 20. Qualitative data was being analyzed in meaningful content description whereas quantitative data was being analyzed in numerical values. Findings of this study revealed that recruiting trained human power, organizing local tour guide associations, making linkage with tour operators, developing tourist guidebook, installing tourist information centers, enhancing promotion and marketing of tourism destinations, information update, improving infrastructures development, and installing accommodation deliverers are the major opportunities to enhance tourism industry development in the Region.
\end{abstract}

Keywords: Tourism, Tourism Industry, Opportunities, Gambella Region

\section{Introduction}

Tourism is movement of people for recreation and leisure [1]; is stay of people outside their usual environment for personal, business or professional purposes [2]. Currently, it is one of the increasingly growing industries globally [3]. It has supporting millions and generating about $10 \%$ of global Gross Domestic Product (GDP) [4]. Tourism industry is one of the leading sectors of the world economy [5]; is a means of important source of income, employment and wealth in many countries [3]; is one of the best ways to earn foreign currency [6]; is currently emerging as one of the most important economic sectors in the world [4]. Tourism industry comprises a set of industries or activities which encompasses human behavior, use of resources, and interactions with other people, economies and environments [7]. It offers economic, social, cultural, intellectual, political and environmental benefits [6]. Ethiopia has huge tourism potentials like natural, non-natural, historical and cultural resources. Although Ethiopia is known with an everincreasing international tourist flow, it is one of the lowest tourist flow benefit recipient countries [8,9]. Regardless of the presence of the tourism resources, the development of tourism industry in Ethiopia is still in an infant stage [10,11]. In Ethiopia, tourism industry which is potential economic sector has not been given due attention until very recently. But, nowadays, tourism industry development in Ethiopia is get increasing interest of attention [10, 12]. 
Gambella People's National Regional State is one of the beautiful tourism destinations of the country which is located at Southwest of Ethiopia. It has gifted with a wealth of natural, non-natural, historical and cultural tourism resources [13]. However, according to the study [10] it seems that the Gambella Region receives fewer tourists relatively compared to other regions. And, also the region is not listed under famous tour and travel operators package. There are various factors hindering tourism industry development in the region like inadequate trained human power, lack of tourist information centers, weak promotion and marketing strategies, lack of local tour guide associations, weak infrastructure development, and the like [14]. Yet, inadequate study has done on identifying opportunities to enhance tourism industry development in the region. Hence, the current study addresses the above specified problem and contributes to the enhancement of tourism industry development in the Gambella Region.

\section{Methodology}

\subsection{Study Area Description}

The study was conducted from June, 2018/19 - May, 2019 in the Gambella Region. Gambella People's National Regional State is located in the South-western part of Ethiopia about $777 \mathrm{~km}$ away from Addis Ababa, the capital city of Ethiopia. It has been situated in the lowlands of Baro-
Akobo River Basin between latitudes $6^{0} 22^{\prime}$ to $8^{0} 37^{\prime}$ North and longitudes $33^{0} 10^{\prime}$ to $35^{\circ} 50^{\prime}$ East. Approximately, it has a total area of $34,063 \mathrm{~km}^{2}$ of land [15].

The region borders with Benishangul Gumuz and Oromiya region to the North; Southern Nations, Nationalities and People's Regional State (SNNPRS) and the Sudan Republic to the South; Oromiya and SNNPRS to the East and the Sudan Republic to the West. The region encompasses three zones; namely Anywaa Zone, Nuer Zone and Majang zone; and comprises 12 woredas, Itang special woreda, and Gambella town administration. The Anywaa zone: consists of Gog, Abobo, Jor, Abol, and Dimma woredas; Nuer zone consists of Jikaw, Makuey, Lare, Wanthowa and Akobo woredas and Majang zone consists of Godere and Mengeshi Woredas $[15,16]$.

The average temperature of the Region is $27^{\circ} \mathrm{c}-33^{\circ} \mathrm{c}$ and the annual rainfall amount ranges from $900 \mathrm{~mm}-2200 \mathrm{~mm}$ [17]. The region experiences unimodal rainfall characterized by heavy rainfall from May to October and low precipitation from November to April [15]. The Region has a total population of $495,625,51 \%(252,769)$ males and $49 \%$ $(242,856)$ female [18]. It has being inhabited by the five indigenous ethnic groups and others nationalities. The five indigenous ethnic groups are Anywaa, Nuer, Majang, Komo and Opo; besides, the other Nationalities of Ethiopia who have been living in the region for such a long time in harmonization.

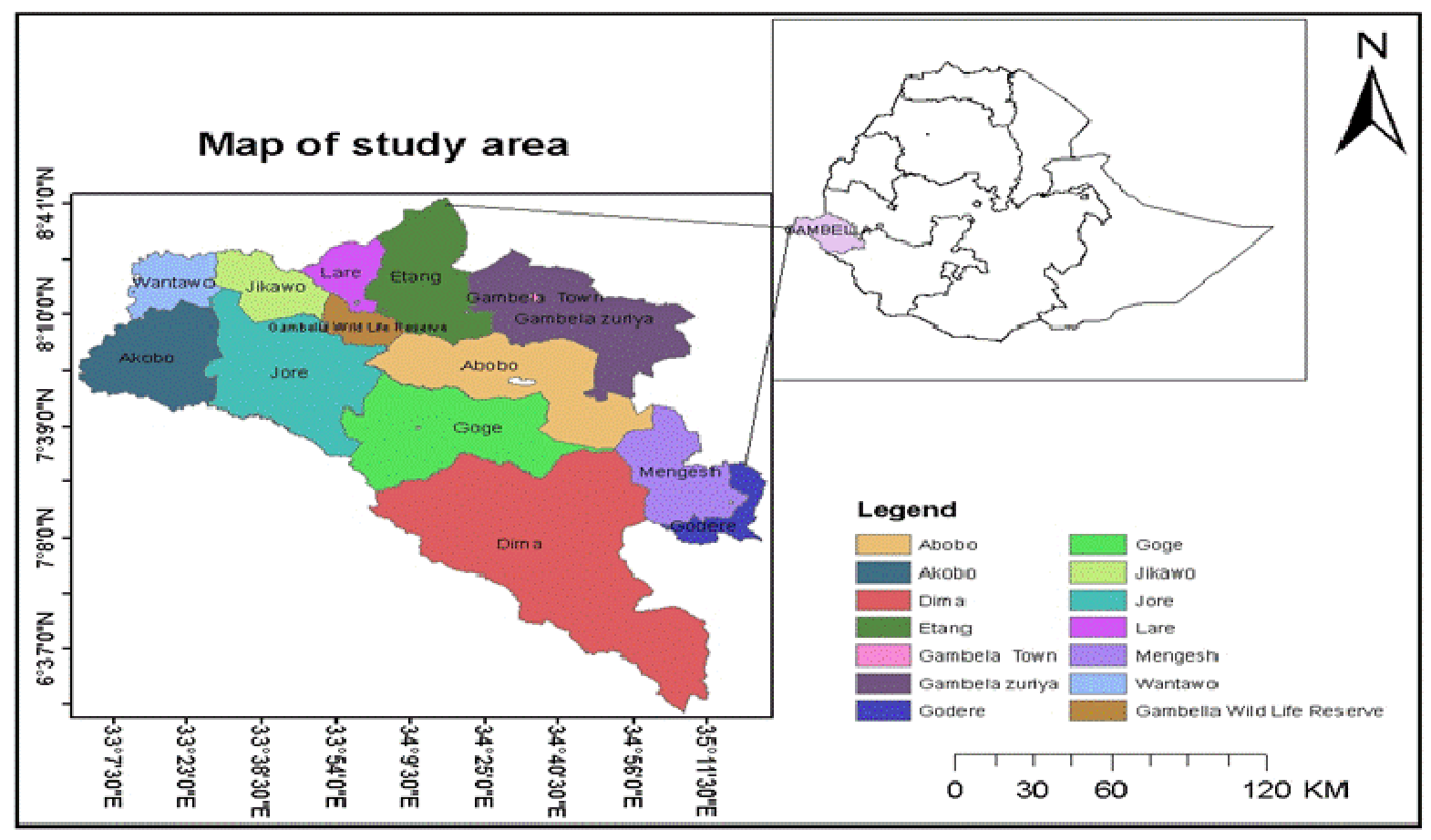

Source: Processed using Arc-GIS 10.3 software, GCS_Adindan

Figure 1. Map of the Study Area.

\subsection{Sampling Procedures}

The population of this study comprises three zones of Gambella region with their twelve woredas (Gog, Abobo, Jor,
Abol, Dimma, Jikaw, Makuey, Lare, Wanthowa, Akobo, Godere, and Mengeshi Woredas. It also involves Itang special woreda and Gambella town administration. In this 
particular study, the non-probability sampling technique (purposive sampling) was being employed to get relevant data from the respondents. Accordingly, key informants from three zones $(n=15)$, thirteen districts $(n=65)$, Gambella National Park office $(n=5)$, Gambella Culture and Tourism Bureau ( $n=5)$, Gambella Tourism Organization Office $(n=5)$, Gambella Culture, History and Heritage Research Directorate $(n=4)$ and Gambella Government Communication Office $(n=4)$, altogether 103 respondents were purposively involved. Selection criteria were: i) their position in a zone, districts or kebeles, ii) their level of knowledge and experience to the tourism industry iii) the most senior tourism related experts and iv) the most relevant individual who can give crucial data to achieve the objectives of the research.

\subsection{Data Collection Methods and Analysis}

There are three zones and thirteen woredas in the Gambella Region. Since it is difficult for a single person to collect data from those zones and woredas, data collectors from Gambella Tourism Organization Office (senior tourism experts and those who can easily communicate and gather data from the informants) were purposively selected. Hence, discussion was held with data collectors how to collect data from the three zones and thirteen woredas. Preliminary field visitation and data collection was also done together. Gambella Tourism Organization Office experts further gave training for other kebele level data collectors as a necessity. Kebele level data collectors were given full orientation before they were left alone. In all circumstances, monitoring, seldom field visit, crosschecking and verification were done to ensure the reliability of the data. According to the scheduled plan, in-depth interview using open-ended questions has been held with purposively selected key informants from regional, zonal and woreda level. Respondents were being given the opportunity to express their ideas, opinions, feelings, and knowledge about opportunities to enhance tourism industry development in the Region. Furthermore, the research crew was also made field observation through recording important information, note taking, photo camera capturing, etc. regarding opportunities. Likewise, secondary data sources (published documents, articles, books, unpublished data, archives, brochures, etc.) were being referred for the further clarification of the data.

The data gathered first edited, categorized, arranged and organized before encoding into the software. Frequency and percentages were calculated using SPSS software version 20 and charts and graphs were used to show results. Qualitative data was being analyzed in meaningful content description with text explanations whereas quantitative data was being analyzed in numerical values. Likewise, data collected through field observation were being analyzed in a content descriptive way to relevant meaning and summarization.

\section{Results and Discussions}

\subsection{Socio-economic Characteristics of the Respondents}

In this specific study, demographic characteristics like sex, education level, income levels, age categories, as well as the marital status of the respondents were being observed. As table 1 shown below about $83.5 \%$ of the respondents were males. Concerning education level, most of the respondents were educated one (first-degree holders) $(74.76 \%)$, and $22.33 \%$ of the respondents were diploma holders. Most of the respondents $(68.93 \%)$ were between the ages category of $26-$ 35 whereas a few respondents $(6.8 \%)$ were in the age interval of 46-55. Concerning marital status, most of the respondents were being married $(95.15 \%)$ (table 1$)$.

Table 1. Socio-economic characteristics of the sampled population ( $n=103)$.

\begin{tabular}{|c|c|c|c|c|c|c|c|}
\hline Variables & & Frequency & Percent & Variables & & Frequency & Percent \\
\hline \multirow{2}{*}{ Sex } & Male & 86 & 83.5 & \multirow{3}{*}{ Income levels (in ETB) } & $2000-3000$ & 22 & 21.36 \\
\hline & Female & 17 & 16.5 & & $3000-400$ & 39 & 37.86 \\
\hline \multirow{2}{*}{$\begin{array}{l}\text { Education } \\
\text { levels }\end{array}$} & Master degree & 3 & 2.91 & & $>4000$ & 42 & 40.78 \\
\hline & Diploma & 23 & 22.33 & \multirow{3}{*}{ Age categories (in year) } & $26-35$ & 71 & 68.93 \\
\hline \multirow{2}{*}{ Marital status } & Married & 98 & 95.15 & & $36-45$ & 19 & 18.45 \\
\hline & Single & 5 & 4.85 & & $46-55$ & 7 & 6.8 \\
\hline
\end{tabular}

Source: Field Survey (2018/19)

\subsection{Opportunities to Enhance Tourism Industry Development in the Gambella Region}

In order to enhance tourism industry development in the region and to generate at least minimum benefit from the tourism industry sector, the following opportunities were identified (Figure 2).

\subsubsection{Recruiting Trained and Skillful Human Resources}

Educated, trained, knowledgeable and skillful experts in tourism sector highly contribute to the tourism development. For sustainable tourism development, about 81(20.66\%), $76(19.39 \%)$ and $67(17.09 \%)$ respondents underlined that recruiting specialized experts is primary action specially in Gambella Culture \& Tourism Bureau, Gambella Tourism Organization and Zonal and Woreda administrations respectively. About 63(16.07\%) of informants are also indicated that Gambella National Park office should fulfill vacant positions in tourism and wildlife specialized experts for better conservation and to enhance tourist flows to the National Park as well as to the region.

\subsubsection{Awareness Creation and Advertisement in Public Places}

Local communities, experts, stakeholders, investors, 
service delivers, etc. should be aware and understand the value of tourism industry development as well as existing tourism potentials of the region. Similarly, they should be informed challenges of tourism development in the region as well should play their respective roles and responsibilities. On behalf of this, informants 78(22.67\%) and 72(20.93\%) emphasized that Gambella Culture and Tourism Bureau and Gambella Tourism Organization should take major role in awareness creation and advertisement of tourism potentials. As well, about $61(17.73 \%)$ of respondents stressed that Gambella National Park office experts should enhance awareness of local community in order to minimize pressures on the tourism potentials of the park. Gambella Government Communication Office is also expected to enhance advertisement of tourism potentials of the region in the public places and festivals.

\subsubsection{Organizing Local Tour Guide Associations and Creating Linkage with Tour and Travel Operators}

Tour guides are "ambassadors" of the certain country, region, state, culture, etc. through building healthy image of the destinations. Henceforth, local tour guide associations should be formed for sustainable tourism development of the region. They should understand code of conducts, trained and certified to become a good tour guide of the region. In order to form visible tour guide association in the region, about $77(23.48 \%)$ and $72(21.95 \%)$ of key informants indicated that Gambella Culture and Tourism Bureau and Gambella Tourism Organization should play significant role with other concerned stakeholders. About $65(19.82 \%)$ of respondents stated that respective Zonal and Woreda Administration should gave attention in identifying capable youths, giving trainings and working in close collaboration with relevant stakeholders.
Similarly, the role of tour and travel operators is undeniable in tourism industry development in the certain place. They can make sound enough promotion of certain tourism destination. A tourism destination should be known by influential tour and travel operators in order to attract international as well as domestic visitors. It should be under the list and travel circuit of large tour and travel operators. Local tour guide associations should create linkage and make soft communication with huge tour and travel operators. Regarding this, about 75(23.08\%) and 71(21.85\%) of respondents justified that Gambella Culture and Tourism Bureau and Gambella Tourism Organization should take large share in forming local tour guide association as well as linking them to the tour and travel operators. On the other hand about 62(19.08\%) informants stressed that Gambella National Park office also has to make connection with known tour and travel operators and agencies in order to make the park being visited by the international visitors.

\subsubsection{Launching Tourist Information Centers}

Tourist information centers give detailed information about available destination to be visited, what to be visited, when to be visited, with whom to be visited, how to go there, etc. for the visitors. The absence of tourist information center hinders visitors to come and visit the tourism destinations although it is sound enough to be visited. Tourist information centers should be placed at national, regional, zonal as well as woreda level in order to avoid confusion and to make destinations easily accessible for visitors. To achieve this in Gambella Region, about $79(21.24 \%), 75(20.16 \%)$ and 64(17.20\%) of informants emphasized that Gambella Culture and Tourism Bureau, Gambella Tourism Organization and Gambella National Park office have to play significant role respectively.

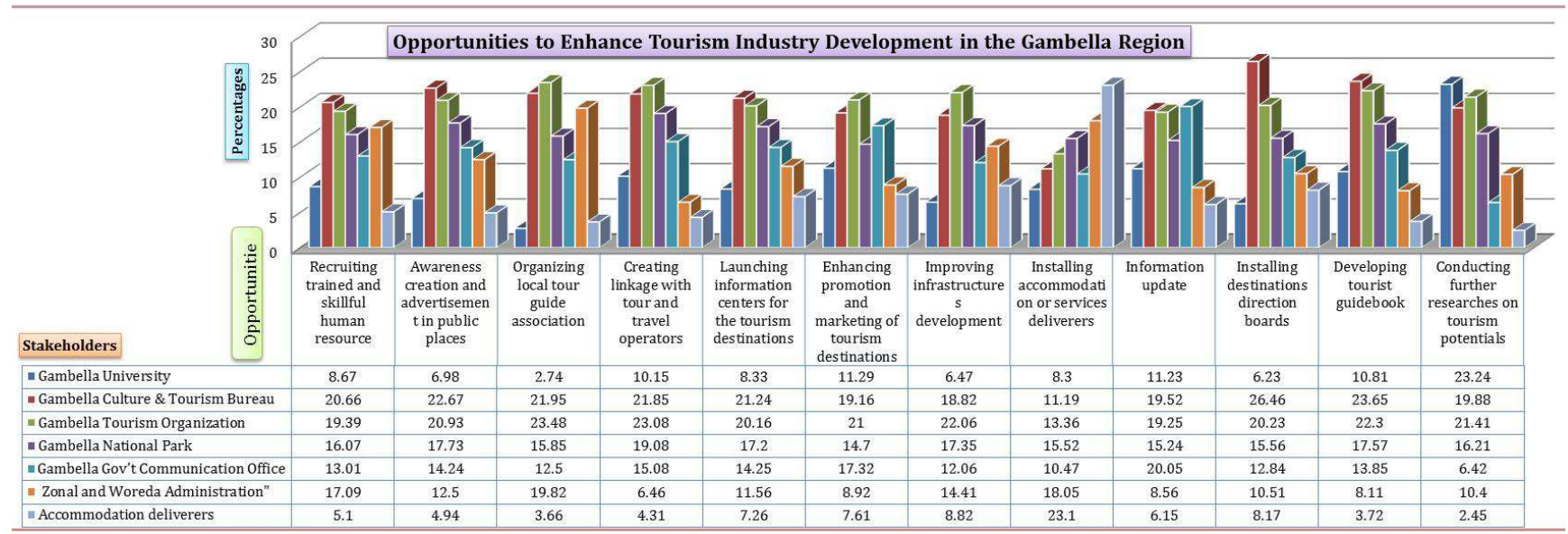

Source: Field Survey $(2018 / 19)$

Figure 2. Respondents'view concerning opportunities to enhance tourism industry development in the Gambella Region.

\subsubsection{Enhancing Promotion and Marketing of Tourism Destinations}

Well-designed promoting and marketing strategies are core process in the development of tourism industry. It is vital activity to make known existing tourism potentials and products. If there is weak promotion and marketing strategies, destinations may be left unvisited although it has marvelous tourism potentials. According to respondents' perception, the major concerned stakeholders are Gambella Tourism Organization, Gambella Culture and Tourism Bureau and Gambella Government Communication office in 
order to promote available tourism potentials and design marketing strategies. Henceforward, about 80 (21\%), 73 $(19.16 \%)$ and $66(17.32 \%)$ of respondents emphasized that mentioned offices should play significant role in tourism promotion and designing applicable marketing strategies. They have to boost up tourism promotion through developing websites, using social Medias, dissemination flyers and brochures, making workshops, participating and information sharing in special tourism events, etc.

\subsubsection{Improving Infrastructures Development and Installing Accommodation Deliverers}

Infrastructure like road, telecom, internet cafes, campsites, water facilities, banking systems, resting places, etc. is the major asset in the tourism industry development. In order to enhance infrastructures development, about 75(22.06\%), $64(18.82 \%)$ and $59(17.35 \%)$ of key informants underlined the Gambella Tourism Organization, Gambella Culture and Tourism Bureau and Gambella National Park has the leading responsibility to improve infrastructure to the destinations as much as possible. However, informants stressed that it is not only the mandate of the mentioned offices but also it needs the collaboration, integration, commitment and contribution of all concerned organizations/offices like Road Authority, accommodation delivers, investors, NGOs, politicians, etc. Informants $49(14.41 \%)$ also highlighted that respective zonal and woreda administrations shall stand together to improve infrastructure facilities till to the specific tourism destinations in the Region.

On the other hand, Standardized accommodation deliverers to both international and domestic visitors are backbone for the continuous development of tourism industry. Visitors need modernized as well as cultural accommodation/services delivering centers. Providing modernized and cultural food, drinks, refreshments, bedrooms, bathing rooms, music, etc. are crucial activities that extends the stay of visitors in a certain destination area. Respondents, about 64(23.10\%) are ensured that accommodation operators should take the leading portion to provide standardized services for the international and domestic visitors. Besides to this regional government, zonal and woreda administrators should create conducive environment to accommodation/services operators to install standardized hotels, lodges, pensions, guest houses, etc. at the regional, zonal and woreda level. In support of this idea, about 50(18.05\%) of respondents stressed that government bodies (regional, zonal and woreda level) have to show remarkable role. On the other hand, about 43(15.52\%) informants emphasized that Gambella National Park has to install environmentally friendly accommodation delivering centers (lodges, campsites, bathrooms, toilets, etc.) for the overnighting visitors as well as for others.

\subsubsection{Information Update}

Developing website, updating information and giving timely data for visitors regarding destinations is essential tool in announcing changes in existing and new tourism products. Right information should be timely updated in order to build trustworthy among visitors. About 75(20.05\%), 73(19.52\%) and $72(19.25 \%)$ informants directed that Gambella Government Communication Office, Gambella Culture and Tourism Bureau and Gambella Tourism Organization respectively should undertake regular information update of existing and new tourism products of the region. As well, about $57(15.24 \%)$ of informants showed that Gambella National Park should design its website and update information concerning existing and new tourism products.

\subsubsection{Installing Tourism Destinations Hoarding Boards}

Properly placed and designed destinations direction boards can lead visitors directly to the area without confusion. Potential tourism destinations should be indicated by direction hoardings, billboards, posters, etc. in environmentally friendly way. It should install in the proper place and indicate the name of the tourism destination, distance, what to visit there, trekking routes, viewpoints, etc. Hence, about $68(26.46 \%)$ and $52(20.23 \%)$ of informants suggested that Gambella Culture \& Tourism Bureau and Gambella Tourism Organization respectively should install the major direction hoardings in the right place which shows major tourism destinations of the region and its brief description. Likewise, about $40(15.56 \%)$ of respondents pointed out that Gambella National Park should fix direction hoardings at the right place in the town, around Park and inside the Park. It shall show directions, distance, available fauna and flora species, trekking routes, forest walking areas, wetland areas, rivers, lakes, waterfalls, campsites, resting areas, and some cautions.

\subsubsection{Developing Tourist Guidebooks}

Tourist guidebooks provide insights to visitors and initiates new visitors to the destinations. About 70 (23.65\%) and 66 $(22.30 \%)$ of informants preferred that regional tourist guidebook should be developed by Gambella Culture \& Tourism Bureau and Gambella Tourism Organization respectively. It should comprise all relevant elements and shall develop enthusiasm among visitors to come and visit Gambella Region tourism potentials. Likewise, around 52(17.57\%) informants said that Gambella National Park develops and disseminate tourist guidebooks. Both regional and Gambella National Park tourist guidebooks shall be accessible for visitors in different places like information centers, accommodation delivering centers, youth centers, etc.

\subsubsection{Conducting Further Researches on Tourism Potentials}

Since Gambella Region is vast as well its tourism potentials, further and deep study on identifying opportunities should be carried out. On this regard, about $76(23.24 \%)$ informants underlined that the Gambella University should carry out further study for more inventory of tourism potentials, factors affecting the development of tourism industry and potential strategies. About 70(21.41\%) and $65(19.88 \%)$ of informants highlighted that Gambella 
Tourism Organization and Gambella Culture \& Tourism Bureau should conduct researches jointly in collaboration for the success and sustainable tourism industry development in the region. Similarly, about 53(16.21\%) of respondents pointed out Gambella National Park in collaboration with other stakeholders has to conduct identification of further tourism potentials (wildlife resources, lakes, rivers, mountains).

\section{Conclusion}

Tourism industry plays significant role in eradicating poverty, job opportunity creation, good image building, sharing best experiences, and international communication. Gambella People's National Regional State is endowed with various tourism potentials to attract international as well as domestic tourists. It has gifted with natural tourism potentials (water bodies, lakes, rivers, waterfalls, mountains, natural bridges, caves, wetlands, and valleys); manmade tourism potentials (bridges, ponds, dams, caves, reservoirs, museums and galleries); historical tourism destination sites (buildings, ancient burial places, inland port); and the Region is home of distinctive cultural tourism potentials (ccultural foods, drinks, dressing styles, cultural music, dance, handicrafts, authentic folklores, folkdances, local markets andlocal festivals). In spite of its wonderful tourism potentials, tourism industry development is still in infant stage. To enhance tourism industry development in the Region collaboration, integration, commitment and significant contribution of all concerned stakeholders is vital activity. A single stakeholder may not ensure sustainable tourism industry development in the region. Therefore, implementing the identified opportunities on the ground may result in tourism industry development in the Region. Thus, improving infrastructures (roads, accommodation deliverers, campsites, water facilities, internet cafes, telecommunication, bank services, and electricity) to the tourism destinations is essential with the integration of multiple stakeholders. To install standardized accommodation deliverers (lodges, resorts, hotels) discussing and come up on consensus with capable enterprises like Kurfitu Resort, Paradise Lodge, Haile Resort, Planet Hotel, Buska Lodge, Turmi Lodge, Simien Lodge, Eco-Omo Lodge, etc. is vital options. The other activity in order to develop tourism industry in the region is effective promotion and marketing of available tourism potentials and products. It involves developing and disseminating different brochures, flyers, guidebooks, websites, using internet and social medias, arranging programmes in Media, forming school conservation clubs, workshops, etc. In order to attract both international and domestic visitors, making connection and communication with large tour and travel operators like Ethiopian Tour Operators Association (ETOA), National Tour Operation (NTO), Four Winds Travel and Tour Agent, Awura Tours, Alpha Tour and Travel, etc. is fruitful activity. Local tour guide associations shall be organized to promote existing tourism potentials and linked with these huge tour and travel operators to attract international visitors as wells to involve
Gambella Region under the travel circuit of different tour and travel operators.

\section{Recommendations}

a) Enhancing awareness, collaboration, integration, commitment, recognition and contribution of all concerned stakeholders (government officials, private and public sectors, investors, local communities, experts, accommodation operators, tour and travel operators, tour guide associations, etc.) for the sustainable of tourism industry development in the Region.

b) Undertaking further study on identifying applicable opportunities with the role of multiple stakeholders to enhance tourism industry development in the Region.

\section{Acknowledgements}

We would like to express our wholehearted gratitude to Research Directorate, Gambella University for giving an opportunity to conduct this research and for financial support. Our unreserved gratefulness also goes to $\mathrm{Mr}$. Aychiluhim Aydefer, Mr. Sisay Befikadu, Mr. Deribachew Shewalem and Mr. Pal Gnack (Gambella Culture and Tourism Bureau experts and our primary stakeholders in this particular study) for their support in data collection, collaboration and providing productive ideas while conducting this research. Lastly, we are indebted to our key informants for kindly sharing their time, contributing helpful insights for this work.

\section{References}

[1] United Nations World Tourism Organization (UNWTO) (2012). Annual Report, Madrid, Spain.

[2] United Nations World Tourism Organization (UNWTO) (2013). Tourism and Poverty Alleviation, Madrid, Spain.

[3] World Travel and Tourism Council (WTTC) (2015) Travel and Tourism Economic Impacts.

[4] World Bank (2012). Ethiopia's Tourism Sector: Strategic Paths to Competitiveness and Job Creation. World Bank, Washington DC.

[5] Pratt S (2010). Economic Linkages and Impacts across the Tourism Area Life Cycle. University of the South Pacific, Fiji.

[6] United Nations World Tourism Organization (UNWTO) (2015). World Tourism Barometer, Vol. 13. UNWTO, Madrid, Spain.

[7] Edgell DL and Swanson JR (2013). Tourism Policy and Planning: Yesterday, Today and Tomorrow, 2nd Ed. Routledge, London.

[8] Rachel D and Richard B (2009). Barriers to Implementing Sustainable Tourism Policy in Mass Tourism Destinations. Tourismos: An International Multidisciplinary Journal of Tourism: Volume 5, Number 1, spring 2010, pp. 35-53. http://mpra.ub.uni-muenchen.de/25162/ 
[9] Ministry of Culture and Tourism (MoCT) (2012). Federal Democratic Republic of Ethiopia, Ethiopia's Tourism Sector: Strategic Paths to Competitiveness and Job Creation News Letter No I, (2009). Awash National Park, Ethiopia, 2012.

[10] Ministry of Culture and Tourism (MoCT) (2013). International Visitors' Exit Survey: Phase I. MoCT, Addis Ababa, Ethiopia.

[11] Tadesse Kidane-Mariam (2015). Ethiopia: Opportunities and Challenges of Tourism Development in the Addis Ababa upper Rift Valley Corridor, Department of Geography, Edinboro University of Pennsylvania, Edinboro, USA.

[12] Binayew TG and Yiheyis AY (2016). Sustainable ecotourism potentials and its challenges in Ethiopia: The Awash National Park in Focus. International Journal of Humanities and Social Science Research, 2 (4): 41-49.

[13] Selemon Thomas and Alemken Berihun (2019). Unexplored Natural Tourism Potentials: Gambella People's National Regional State, South West Ethiopia. International Journal of Scientific and Research Publications: Vol. 9 (5). DOI: 10.29322/IJSRP.9.05.2019.p8940. Pp. 334-347.

[14] Selemon Thomas and Alemken Berihun (2019). Factors Hindering Tourism Industry Development: Gambella People's
National Regional State, South West Ethiopia. Global Journal of Management and Business Research: (F) Real Estate, Event and Tourism Management. Vol. 19 (1) Version 1.0.

[15] Lema E, Tefera J, Fikiru M and Adanech A (2017). Assessment of Plant Diversity and Structural Analysis of Majang Forest Biosphere Reserve, Majang Zone, Gambella Regional State, Southwest Ethiopia. MELCA-Ethiopia, Addis Ababa, Ethiopia.

[16] Mathewos M (2017). Analysis and Detection of Land Use and Land Cover Changes Using Remote Sensing Technology on the Landscape of Majang Zone, Gambella Region. MELCAEthiopia, Addis Ababa, Ethiopia.

[17] Wondachew M and Muchie N (2017). Assessment of Traditional Farming andNatural resource Management Practices in Majang Forest Biosphere Reserve, Southwest Ethiopia. MELCA-Ethiopia, Addis Ababa, Ethiopia.

[18] Central Statistical Authority (CSA) (2007). The 2007 Population and Housing Census for Ethiopia. Results at country level, statistical report, Addis Ababa, Ethiopia. 